\title{
Effects of remifentanil on processing of auditory stimuli: A combined MEG/EEG study
}

Citation for published version (APA):

Quaedflieg, C. W. E. M., Münte, S., Kalso, E., \& Sambeth, A. (2014). Effects of remifentanil on processing of auditory stimuli: A combined MEG/EEG study. Journal of Psychopharmacology, 28(1), 39-48. https://doi.org/10.1177/0269881113512036

Document status and date:

Published: 01/01/2014

DOI:

10.1177/0269881113512036

Document Version:

Publisher's PDF, also known as Version of record

Document license:

Taverne

\section{Please check the document version of this publication:}

- A submitted manuscript is the version of the article upon submission and before peer-review. There can be important differences between the submitted version and the official published version of record.

People interested in the research are advised to contact the author for the final version of the publication, or visit the DOI to the publisher's website.

- The final author version and the galley proof are versions of the publication after peer review.

- The final published version features the final layout of the paper including the volume, issue and page numbers.

Link to publication

\footnotetext{
General rights rights.

- You may freely distribute the URL identifying the publication in the public portal. please follow below link for the End User Agreement:

www.umlib.nl/taverne-license

Take down policy

If you believe that this document breaches copyright please contact us at:

repository@maastrichtuniversity.nl

providing details and we will investigate your claim.
}

Copyright and moral rights for the publications made accessible in the public portal are retained by the authors and/or other copyright owners and it is a condition of accessing publications that users recognise and abide by the legal requirements associated with these

- Users may download and print one copy of any publication from the public portal for the purpose of private study or research.

- You may not further distribute the material or use it for any profit-making activity or commercial gain

If the publication is distributed under the terms of Article $25 \mathrm{fa}$ of the Dutch Copyright Act, indicated by the "Taverne" license above, 


\title{
Effects of remifentanil on processing of auditory stimuli: A combined MEG/EEG study
}

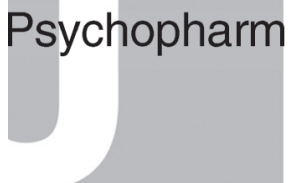

\author{
Conny WEM Quaedflieg ${ }^{1}$, Sinikka Münte ${ }^{2}$, Eija Kalso ${ }^{3}$ \\ and Anke Sambeth ${ }^{1,4}$
}

Journal of Psychopharmacology 2014, Vol 28(1) 39-48 (c) The Author(s) 2013 Reprints and permissions: sagepub.co.uk/journalsPermissions.nav DOI: $10.1177 / 0269881113512036$ jop.sagepub.com

(S)AGE

\begin{abstract}
Remifentanil (Ultiva ${ }^{\oplus}$ ) is a potent ultra-short acting mu-opioid receptor agonist used for perioperative pain treatment and anaesthesia. So far, it is not known how sensitive the cognitive processing of auditory perception elicited by the mismatch negativity (MMN) paradigm is to opioids. The present exploratory study investigated how the opioid remifentanil modulates different stages of auditory processing as reflected in the MMN(m) and P3a(m). We recorded electroencephalography (EEG) and magnetoencephalography (MEG) during auditory stimulation under remifentanil or placebo infusion in 20 healthy participants. For the MMN, a gender effect was found for tones deviating in frequency $( \pm 10 \%)$ from the standard tone. Remifentanil increased the amplitude of the frequency MMN at F3 in females but not in males. No effect of treatment was found for the MMN $(m)$ or the novel P3a(m). These results suggest that while the bottom-up stimulus change detection system for auditory stimuli appears to be relatively insensitive to opioids, the automatic attention switch caused by the change detection seems to be modulated by the opioid system in females. The multiple deviant paradigm including novel sounds is a promising tool for investigating pharmacological manipulation of different stages of auditory processing. Furthermore, combining the two techniques will yield more specific information about the drug effects on $\operatorname{MMN}(\mathrm{m})$.
\end{abstract}

Keywords

Mu-opioid, auditory processing, mismatch negativity (MMN), P3a

\section{Introduction}

The opioid system is involved in physiological functions such as mood, stress and reward, but also in memory acquisition and analgesia (Leppa et al., 2006). There are three types of G-protein coupled opioid receptors: the mu-, delta- and kappa-receptors. The mu-opioid receptor (MOR) is located with high density in the cingulate cortex, thalamus, periaqueductal grey, caudate nucleus, and brainstem, whereas only a small number of mu-receptors have been found in the cerebral cortex and cerebellum (Julien 2005; Leppa et al., 2006; Peng et al., 2012). The specific MOR distribution accounts for the pharmacological effects of drugs acting on MORs, including analgesia, respiratory depression, sedation and nausea (Panzer et al., 2009; Scott and Perry 2005).

A potent ultra-short-acting mu-receptor agonist is remifentanil $\left(\right.$ Ultiva $^{\circledR}$ ) (Beers and Camporesi 2004; Cabanero et al., 2009; Panzer et al., 2009; Scott and Perry 2005), which is administered intravenously and used for pain treatment and anaesthesia (Battershill and Keating 2006; Breen et al., 2005; Brush and Kress 2009; Dahaba et al., 2004). Remifentanil displays some unique pharmacokinetic properties. It is organ-independently metabolized by esterases present in tissues and plasma. Moreover, remifentanil has a rapid onset of action $( \pm 1.5 \mathrm{~min}$. $)$ and it does not accumulate in the body (Beers and Camporesi 2004; Panzer et al., 2009) minimizing the risk of opioid-induced respiratory depression and providing a short and predictable drug effect window (Lauwers et al., 1998). These unique characteristics set remifentanil apart from other opioid agents and make this opioid suitable for the research of the cerebral mechanisms of the opioid system.

Direct information about ongoing cerebral processes can be acquired by using electroencephalography (EEG) and magneto-encephalography (MEG). The former detects both radial and tangential currents located in cortical gyri and fissures, whereas the latter is most sensitive for tangential currents and is less influenced by distortions of different head tissues and the skull (e.g. Hillebrand and Barnes, 2002; Kahkonen 2006; Lopes da Silva 2010; Papanicolaou 1995). Combining MEG and EEG makes it possible to assess the effects of pharmacological agents, such as opioids, on different aspects of information processing in the brain which can be assessed using event-related potentials/ fields (ERPs/ERFs).

A well-studied auditory ERP is the mismatch negativity $(\mathrm{MMN})$ which is seen as a negative deflection in the EEG between 100-250 ms after stimulus onset (Alho et al., 1993; Garrido et al., 2009). It is evoked in an oddball task by deviant stimuli which do

${ }^{1}$ Faculty of Psychology and Neuroscience, Maastricht University, The Netherlands

${ }^{2}$ Helsinki University Central Hospital, Children's Hospital, Department of Anaesthesiology, Helsinki, Finland

${ }^{3}$ Pain Clinic, Department of Anaesthesiology, Helsinki University Central Hospital, Helsinki, Finland, and Institute of Clinical Medicine, University of Helsinki, Helsinki, Finland

«BioMag Laboratory, HUS Medical Imaging Center, Helsinki University Central Hospital, Helsinki, Finland

\section{Corresponding author:}

Conny Quaedflieg, Faculty of Psychology and Neuroscience, Maastricht University, P.0. Box 616, 6200 MD Maastricht, The Netherlands.

Email: conny.quaedflieg@maastrichtuniversity.nl 
not match a neural memory trace formed by regular sounds (Näätänen et al., 2011). The predominant theory suggests that the MMN reflects auditory sensory memory and provides an index of pre-attentive information processing (Näätänen et al., 1989, 2011) as the MMN is elicited even when the subject is not paying attention (Escera et al., 1998; Kujala et al., 2007; Woldorff et al., 1991).

The MMN is generated by a temporal-frontal network and comprises two subcomponents reflecting different phases of detection and orienting to stimulus features. The early, tangentially oriented component originates bilaterally from the auditory cortex and is involved in the automatic detection of sound change (Garrido et al., 2009; Rinne et al., 2000). This early component can be measured with EEG and MEG. The involuntary bottom-up attention shift to this sound change elicits a late MMN subcomponent originating in the frontal lobe (Garrido et al., 2009; Giard et al., 1990; Näätänen et al., 2007; Rinne et al., 2000). With MEG it is impossible to detect this late component, suggesting that it has either a deeper or a radially oriented source (Kenemans and Kahkonen, 2011).

Other ERP components which can be elicited by the MMN paradigm are the N1 and the P3a. It is suggested that the N1 reflects the build-up of an auditory sensory-memory trace (Näätänen and Picton, 1987). In addition to the N1, a P3a wave can be triggered by the MMN paradigm if the sound is sufficiently deviant. The P3a is a positive deflection maximal between 250 $350 \mathrm{~ms}$ after stimulus onset and has been associated with the topdown controlled switching of attention towards the deviant event (e.g. Friedman et al., 2001; Polich 2007). In addition, several studies found a larger P3a after novel sounds compared with deviants (Ceponiene et al., 2004; Escera et al., 1998; Maatta et al., 2005).

The MMN has traditionally been assessed in a passive oddball paradigm in which deviant infrequent sounds $(\approx 20 \%)$ are embedded among frequent tones $(\approx 80 \%)$. A newer method to measure $\mathrm{MMN}$ is the multiple deviant paradigm (Näätänen et al., 2004), in which every second sound is one of five different deviants. This multiple deviant paradigm gives a better estimate of sound discrimination associated with normal listening than the oddball paradigm (Kujala et al., 2007). In this study, a sixstimuli multiple deviant paradigm was used (including standard tones $(50 \%)$, four different deviant tones and novel sounds; see also Pakarinen et al., 2007; Sambeth et al., 2006, 2009) as a model for sound processing. The MMN has been extensively used as a model of auditory processing in psychopharmacological studies (see for a review Kenemans and Kähkönen, 2011) and clinical populations. For example, a delayed and reduced MMN has been found in chronic pain patients, indicating preattentive processing abnormalities (Dick et al., 2003; Yao et al., 2011). Moreover, opioid receptors have been localized in the inferior colliculus, suggesting a role for the opioid system in auditory processes (Tongjaroenbuangam et al., 2006). In this exploratory study, EEG and MEG were combined in order to obtain a comprehensive view of how remifentanil modulates different stages of auditory processing as reflected in the $\mathrm{MMN}(\mathrm{m})$ (i.e. automatic processing) and $\mathrm{P} 3 \mathrm{a}(\mathrm{m})$ (i.e. top-down controlled processing). This information is needed for the future exploration of the MMN as an objective measure to study the effect of opioid therapy on the disruptive effects of chronic pain on $\mathrm{MMN}$, and more generally as a potential marker of the painrelieving effects of analgesics. Given the exploratory nature of this study, no a priori hypotheses were formulated.

\section{Methods and materials}

The present experiment was part of a larger study performed at the Helsinki University Central Hospital. In this study, we investigated the effects of remifentanil on brain activity, and particularly how remifentanil modulates the processing of auditory, visual and somatosensory stimuli in healthy individuals. To measure the central nervous system effects of remifentanil, subjective effects of remifentanil were assessed by using visual analogue scales (VAS). The effects of remifentanil on auditory processing were assessed with the MMN paradigm, using a randomized, double-blind, placebo-controlled, cross-over within-subjects experiment. Randomization was established by a research nurse of the Pain Clinic, who did not participate in the MEG/EEG measurements.

\section{Participants}

Twenty healthy adults (10 males and 10 females) between 18 and 40 years old (mean age males: 22 years; mean age females 24 years) were recruited to participate in this study via email advertisement at the Helsinki University. Participants were included if they had a body mass index between 18.5 and 30. Participants were excluded if they had a history of psychiatric, neurologic or cardio-vascular disease or if they had indicated that they smoke, use analgesics, medicines that affect the central nervous system or abuse alcohol, drugs or psychostimulants (more than 5 cups of caffeine-containing drinks per day). Women were included if they were in the follicular phase of the menstruation cycle on the test days. The participants were treated in accordance with current ethical guidelines. The study plan was approved by the ethical committee of Helsinki Central University Hospital and the National Agency of Medicines, Helsinki, Finland. All participants signed a written informed consent and were given a monetary compensation (€75) for their participation.

\section{Stimulus presentation and tasks}

The auditory stimuli were presented (Presentation ${ }^{\circledR}$ software version11.3) binaurally via one panel speaker located right in front of the participant at $5 \mathrm{~m}$ with the same distance to both ears (Panphonics Sound-Shower 2). To ensure that there were no differences between drug conditions in the ear position relative to the source of the auditory stimuli, the head position of every participant was determined at the beginning of every task by measuring the magnetic fields produced by the head position indicator (HPI) coils in relation to the cardinal points on the head (nasion, left and right pre-auricular points) that were determined before the experiment using Isotrack 3D digitizer (Polhemus, Colchester, VT, USA). An adapted version of the multiple deviant paradigm (Näätänen et al., 2004), including six stimulus types, was used in this study (see Table 1 and also Sambeth et al., 2006). In this passive oddball task, deviant infrequent tones and novel sounds were embedded among standard tones. The four deviant types differed only in one acoustic feature; either in frequency $( \pm 10 \%)$, duration (shortening by $50 \mathrm{~ms} ; 500 \mathrm{~Hz}$ ), intensity $( \pm 10 \mathrm{~dB} ; 500 \mathrm{~Hz}$ ) or by a silent gap in the middle of the tone $(7 \mathrm{~ms} ; 500 \mathrm{~Hz})$. The novel stimuli consisted of sounds of one of the following three stimulus categories: animal, human and mechanical sounds (see Table 1 for the stimuli specifications). The task consisted in total of 615 standard tones and started with 15 standard tones. The remaining 
Table 1. The six multiple deviant stimuli oddball paradigm. The paradigm consisted of 120 sequences, each sequence lasted $5 \mathrm{~s}$ and consisted of 10 stimuli; five standard stimuli alternated with the five deviant stimuli. All deviant stimulus types and the novel sounds were randomly present once in each sequence. The four deviant types differed from the standard tone in only one acoustic feature and the novel consisted of sounds of one of the following three stimulus categories: animal, human and mechanical sounds.

\begin{tabular}{llllll}
\hline & Duration $(\mathrm{ms})$ & Frequency $(\mathrm{Hz})$ & Amplitude $(\mathrm{dB})$ & Probability in \% \& total number () \\
\hline Stimulus & Standard & 75 & 500 & 70 & $50 \%(600)$ \\
& Frequency & 75 & 450550 & 70 & $10 \%(120)$ \\
Intensity & 75 & 500 & 6080 & $10 \%(120)$ \\
Duration & 25 & 500 & 70 & $10 \%(120)$ \\
Gap & 34 & 500 & & $10 \%(120)$ \\
& $7 \mathrm{~ms}$ gap 34 & n.a. & & & $10 \%(120)$ \\
& Novel & 300 & & & $3.33 \%(40)$ \\
& - Animal & & & $3.33 \%(40)$ \\
& - Human & & & $3.33 \%(40)$ \\
& - Mechanical & &
\end{tabular}

$50 \%$ of the stimuli consisted of the four types of deviant tones and novel sounds (120 stimuli each, probability of $10 \%)$. The task consisted of 120 sequences in which all deviant stimulus types and the novel sounds were present once in each sequence, and two successive deviant stimuli were always of different types. The stimulus onset asynchrony was $500 \mathrm{~ms}$. The participants watched a self-selected video with the sound turned off during the recording.

The subjective effects of remifentanil were assessed by using VAS consisting of three items related to subjective feelings and adverse effects of the drug, e.g. sleepy-awake, happy-sad and confused-clear.

\section{Procedure}

This study consisted of a pretest session and two test days. The pretest aimed to evaluate the individual effects and adverse effects of the study drug, remifentanil. The participants received the opioid remifentanil via an intravenous cannula delivered by a target controlled infusion (TCI) pump (Alaris ${ }^{\circledR}$ Medical Systems, San Diego, California, USA).

The aim of using the TCI system is to reach as rapidly as possible a steady concentration of the drug in the effect site (brain). We used a TCI mode that delivers bolus doses and infusion rates of remifentanil based on a pharmacokinetic model developed by Minto et al. (1997). This model calculates the plasma or effect-site concentrations of the drug taking account the body compartment volumes, transfer of the drug between compartments and the drug elimination rate and covariates such as age, weight, height and gender. The dose of remifentanil ( $1.0 \mathrm{ng} / \mathrm{mL}$ effect-site concentration) and the delivery method were the same during the pretest day and test days; only the duration of infusion was different (pretest day $30 \mathrm{~min}$ vs. test days $60 \mathrm{~min}$ ). This dose was based on previous research demonstrating analgesic effects without excessive sedation and blood-oxygen desaturation, thus demonstrating that it is safe (e.g. Wagner et al., 2001; Wise et al., 2004). Participation in the study was discontinued if, according to the anaesthesiologist, relevant side effects or serious adverse events were observed during the pretest.

The two test days were performed at the BioMag laboratory at the Helsinki University Central Hospital (HUCH). They were identical except for the treatment (placebo or remifentanil) and they were spaced apart by at least 3 days. A test day started with filling in the VAS, preparing EEG, digitization of the headmarker coils using Isotrack 3D digitizer (Polhemus, Colchester, VT, USA) and placing the intravenous cannula for drug infusion. Next, the participant was seated into the MEG device with the helmet in upright position and received the task instructions, whereafter the remifentanil infusion started. The participants were awake during the 60 min-long test battery, which included the MMN oddball paradigm as well as a reaction time task and questionnaires (Munte et al., 2013). The MMN task was administered 25 min after the start of the infusion of the drug.

An anaesthesiologist was present in the shielded room during the whole measurement to continuously monitor the haemodynamic and respiratory functions by clinical means. Moreover, pulse rate, blood pressure and the blood-oxygen saturation level were automatically and continuously monitored during test days with a device situated outside the electromagnetically shielded room (Datex, Engstorm).

\section{Data acquisition}

EEG and MEG measurements were performed in a room isolated from magnetic or electric interferences (Euroshield Ltd., Eura, Finland) at the HUCH BioMag laboratory. The MEG was recorded using a helmet-shaped vectorview whole-head 306-channel magnetometer system (ElektaNeuromag 306, Oy, Helsinki) consisting of 204 planar gradiometers and 102 magnetometers. The position of the subjects head relative to the recording instrument was determined by using four HPI coils, which were placed approximately around the F3, F4, P3 and P4 locations according to the international 10-20 system (Jasper, 1958). Head position was determined at the beginning of every task by measuring the magnetic fields produced by the HPI coils in relation to the cardinal points on the head (nasion, left and right pre-auricular points) which were determined before the experiment using Isotrack 3D digitizer (Polhemus, Colchester, VT, USA).

Simultaneously with the MEG, EEG was recorded at F3, Fz, F4, C3, Cz, C4, P3, Pz and P4 locations using an elastic cap according to the 10-20 system. Two electrodes at the outer canthi of both eyes recorded horizontal eye movements and two 
electrodes above and below the left eye recorded vertical eye movements. The ground was placed on the forehead and the reference electrode was placed on the left mastoid. MEG/EEG data were continuously sampled at $600 \mathrm{~Hz}$ with a band-pass filter of $0.03-200 \mathrm{~Hz}$

\section{Analysis}

Both MEG and EEG data were band-pass filtered between 1-30 $\mathrm{Hz}$ and baseline corrected. Epochs were made for each stimulus type separately from $100 \mathrm{~ms}$ before stimulus onset to $500 \mathrm{~ms}$ after stimulus onset. Epochs containing EOG or EEG changes exceeding $250 \mu \mathrm{V}$ or MEG changes exceeding $3000 \mathrm{fT} / \mathrm{cm}$ were automatically omitted from averages, as were the responses to the first few stimuli of the sequence. The resulting averages included at least 300 artefact-free standards and 50 artefact-free frequency, duration, intensity, gap and novel responses. Grand averages across participants were constructed per stimulus type separately for the remifentanil and placebo condition to determine the mean peak latency. To delineate the $\mathrm{MMN}(\mathrm{m}) / \mathrm{MMN}$, difference waves were obtained by subtracting the response to the standard tones from the responses elicited by the deviant tones or novel sounds. In these grand average difference waves, stimulus-specific peak latencies were determined and were used to construct the time windows of the area reports for the $\mathrm{MMN}(\mathrm{m})$ and $\mathrm{P} 3 \mathrm{a}(\mathrm{m})$. Embedded in this difference wave are both the MMN and the N100. The N100 is also generated in the auditory cortex and sometimes overlaps with the MMN. Yet, they are differently affected by experimental manipulations (Korostenskaja et al., 2007; Umbricht et al., 2000). To make sure that the early peaking N100 did not contaminate our MMN(m), for both the MEG and EEG, the latency of the N100(m) was visually derived from the standard response average. This peak latency was used as reference for the determination of the time window of the $\operatorname{MMN}(\mathrm{m})$. That is, the $\mathrm{MMN}(\mathrm{m})$ came always after the N100 and was measured as mean amplitude over a $60 \mathrm{~ms} \mathrm{(30} \mathrm{ms} \mathrm{before}$ and $30 \mathrm{~ms}$ after) stimulus-specific time window. The range of the time windows used for the $\mathrm{MMN}(\mathrm{m})$ was $120-220 \mathrm{~ms}$ and 110 $210 \mathrm{~ms}$ for the MMN. The P3a(m) was measured as the mean amplitude over a $100 \mathrm{~ms}$ ( $50 \mathrm{~ms}$ before and $50 \mathrm{~ms}$ after) area with a time window of 180-280 ms for the P3a(m) and 190-290 ms for the P3a.

For the MEG data, vector sums were calculated as the mean of two orthogonal gradiometer sensor-pairs centred at the right or left auditory cortex. The mean of vector sums of two adjoining channel pairs with the largest response were used for further analysis. Moreover, dipole fitting was performed, and is displayed in Figure 1, to obtain an estimation of the magnetic field pattern and the polarity of the MMN(m). The dipole strength and latency of the $\mathrm{MMN}(\mathrm{m})$ was estimated with a single equivalent current dipole model found by a least square fit using two separate fixed subsets of 34 gradiometer channels centred at the approximate location of either the right or left auditory cortex (Hämäläinen et al., 1993). Fitting the dipoles was done according to the following criteria: 1) the coordinates of the dipole had to be within the auditory cortex $(x=30-65 y=-25-25 z=30-90)$ with an allowed deviation of $5 \mathrm{~mm}$; 2 ) the goodness of fit had to be 0.7 or higher; 3 ) if the above-mentioned criteria were met, the strongest dipole within the time window of the $\mathrm{MMN}(\mathrm{m})$ response with a correct orientation producing a negative polarity was selected. The dipole analysis was not included in the results section since the above-mentioned goodness of fit criteria was often not met for the remifentanil condition.

The effect of remifentanil on the $\mathrm{MMN}(\mathrm{m})$ and $\mathrm{P} 3 \mathrm{a}(\mathrm{m})$, taking into account the different stimulus types, was assessed using a 2 (Condition: placebo, remifentanil) $\times 5$ (Stimulus Type: Frequency, Duration, Gap, Intensity, Novel) $\times 4$ (EEG Electrode: F3, F4, C3 $\&$ C4) or $\times 2$ (MEG Hemisphere: Right, Left) repeated measures ANOVA with Gender (male, female) as between-subject factor. These analyses revealed a Condition $\times$ Stimulus $\times$ Electrode interaction $(F(12,204)=1.72 ; p=.07)$ and a Condition $\times$ Stimulus $\times$ Hemisphere interaction $(F(4,60)=2.04 ; p=.10)$ at trend level. To further identify the three-way interactions, 2 (Gender) $\times 2$ (Condition) rmANOVAs per stimulus type and hemisphere (MEG data) or electrode (EEG data) were conducted. Because of the exploratory nature of this study, the multiple separate ANOVAs ran, and the notion that we measure the same outcome on multiple electrodes or two hemispheres, correction for the possible increase in type I error was applied. We corrected the EEG data MMN analysis by dividing the alpha of 0.05 by 4 (i.e. four electrodes were included in the analysis), the P3a analysis by dividing the alpha of 0.05 by 6 (i.e. six electrodes were included in the analysis), and the MEG data $M M N(m)$ analysis by dividing the alpha of 0.05 by 2 (i.e. two sensor clusters were included in the analysis). Thus, $p$-values less than $0.013,0.008$ and 0.025 , respectively, were considered as statistically significant.

\section{Results}

In total 22 healthy volunteers were recruited for this study. Two female participants were excluded after the pretest because of adverse effects during the pretest. Specifically, one female experienced dysphoria and the other female had a decrease in blood pressure and she felt dizzy during the remifentanil infusion. The pulse rate, blood pressure and the blood-oxygen saturation level of the 20 participants included in the study were stable.

\section{$M M N(m)$ and $P 3 a(m)$}

Figure 1 shows a grand average of the responses per condition to the standard, frequency and novel sounds across subjects from all the gradiometer channels. The MEG mean amplitudes for difference waves (deviant/novel sound - standard) are presented in Table 2. The ANOVAs per stimuli did not reveal any significant Condition $\times$ Gender interaction or Condition main effect in the left or right hemisphere (all $p$-values $>.025$, see Table 2). For the novel P3a(m), separate ANOVAs per hemisphere did not reveal any significant Condition $\times$ Gender interaction or Condition main effect (all $\mathrm{F}$ values $<1$; p-values $>$.025).

\section{MMN and novel P3a}

The event-related potentials elicited by the MMN paradigm at the F3, F4, C3 and C4 electrode are illustrated in the grand average across participants in Figure 2. The MMN can be detected approximately at $150 \mathrm{~ms}$ in the deviant difference wave (Deviant - standard). In the novel difference wave (Novel - standard) two peaks can be seen representing the MMN and P3a (see Figure 2). Bonferroni-corrected ANOVAs per stimuli per electrode (F3, F4, $\mathrm{C} 3$ and $\mathrm{C} 4)$, revealed a significant Condition $\times$ Gender interaction 


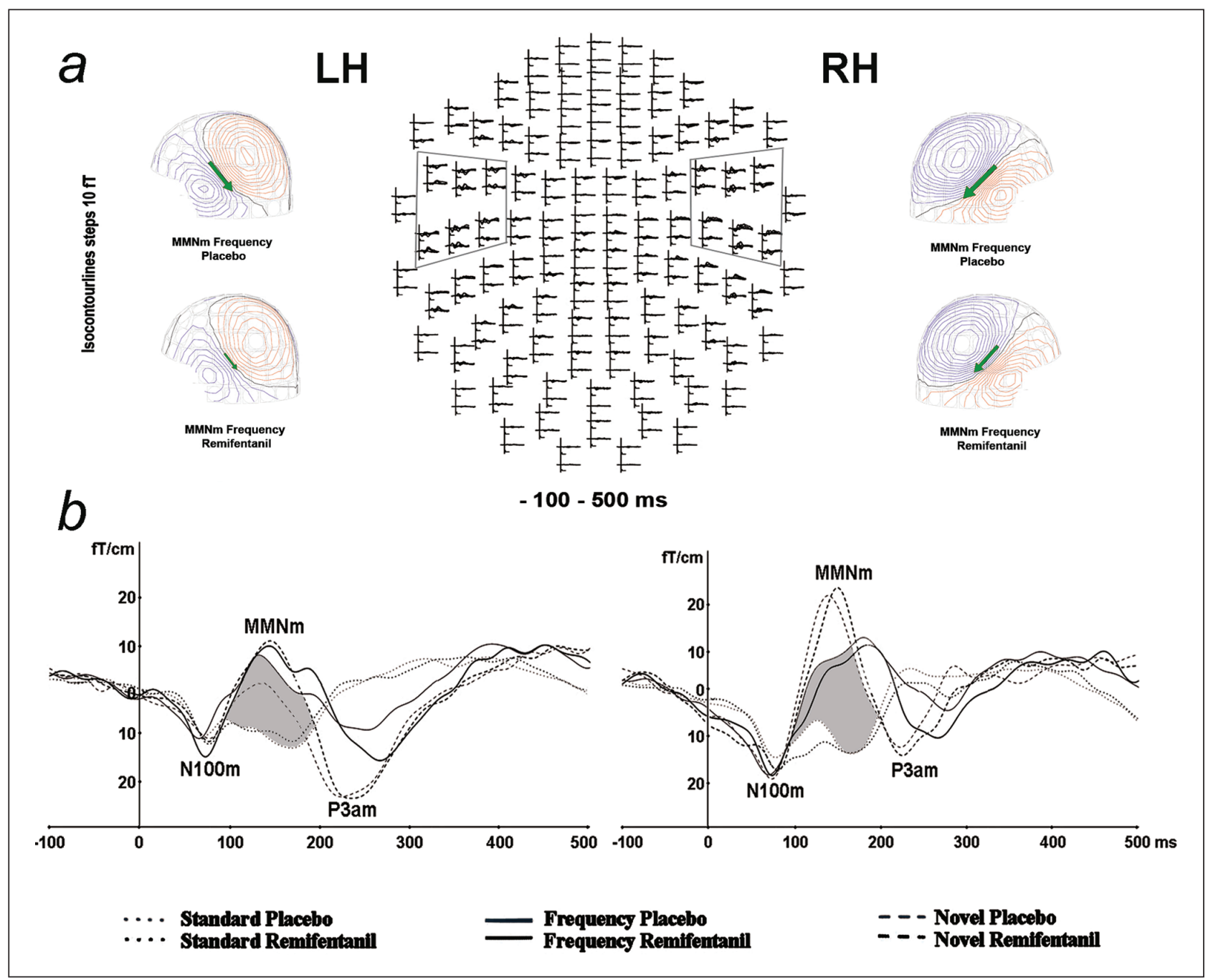

Figure 1. Grand average of the evoked magnetic responses elicited by the MMN paradigm for the standard, frequency and novel sounds across subjects per condition. Panel a 0verview of the whole-head 204 planar gradiometer channels and helmet representations of the field distribution. In the whole-head figure, the left and right auditory cortex channels are encircled. The helmet views illustrate the magnetic field pattern and the arrows the best-fitting equivalent current dipoles (ECDs) for the frequency $\operatorname{MMN}(\mathrm{m})$ in the placebo and remifentanil condition for both hemispheres. Panel $b$ : One enlarged MEG gradiometer channel displaying the ERFs of three stimulus types. The vertical line represents the stimulus presentation and the shadowed area the mismatch negativity for the frequency deviant in the placebo condition.

for Frequency stimuli at F3 $(F(1,16)=7.77 ; p=.013)$. Simple effects per gender revealed a significant main effect of Condition on $\mathrm{F} 3$ in females $(F(1,8)=10.20 ; p=.013)$ with remifentanil increasing the Frequency MMN amplitude but such effect was not evident in males $(F(1,8)=0.53 ; p=.49)$ as shown in Figure 3. All other comparisons fell short of significance (all $p$-values $>.013$ ). For the P3a of novels sounds, separate ANOVAs per electrode did not reveal any significant Condition $\times$ Gender interaction or Condition main effect (all p-values $>.008$; see Table 3 ).

\section{Subjective effects}

Expected behavioural changes were observed during remifentanil administration. Figure 4(a) and (b) summarizes the effect of remifentanil on the VAS items. The ANOVAs per VAS item revealed a Condition $\times$ Gender interaction effect for Feeling Sleepy $(F(1,17)=5.63, p=.03)$. Simple effects per gender revealed that all participants felt sleepier with a larger effect in females (Females: $F(1,8)=37.87, p<.001$; Males: $F(1,9)=$ $8.45, p=.017)$. In addition, participants felt more confused during remifentanil infusion, as shown by a main effect on Confusion $(F$ $(1,18)=17.44, p<.001)$. Remifentanil did not affect mood shown by the non-significant Happy main effect $(F<1)$.

\section{Discussion}

The primary aim of the present study was to investigate the effects of remifentanil on auditory processing measured with a MMN paradigm consisting of six deviant stimuli using a within-subject design. Automatic auditory processing was quantified as the 


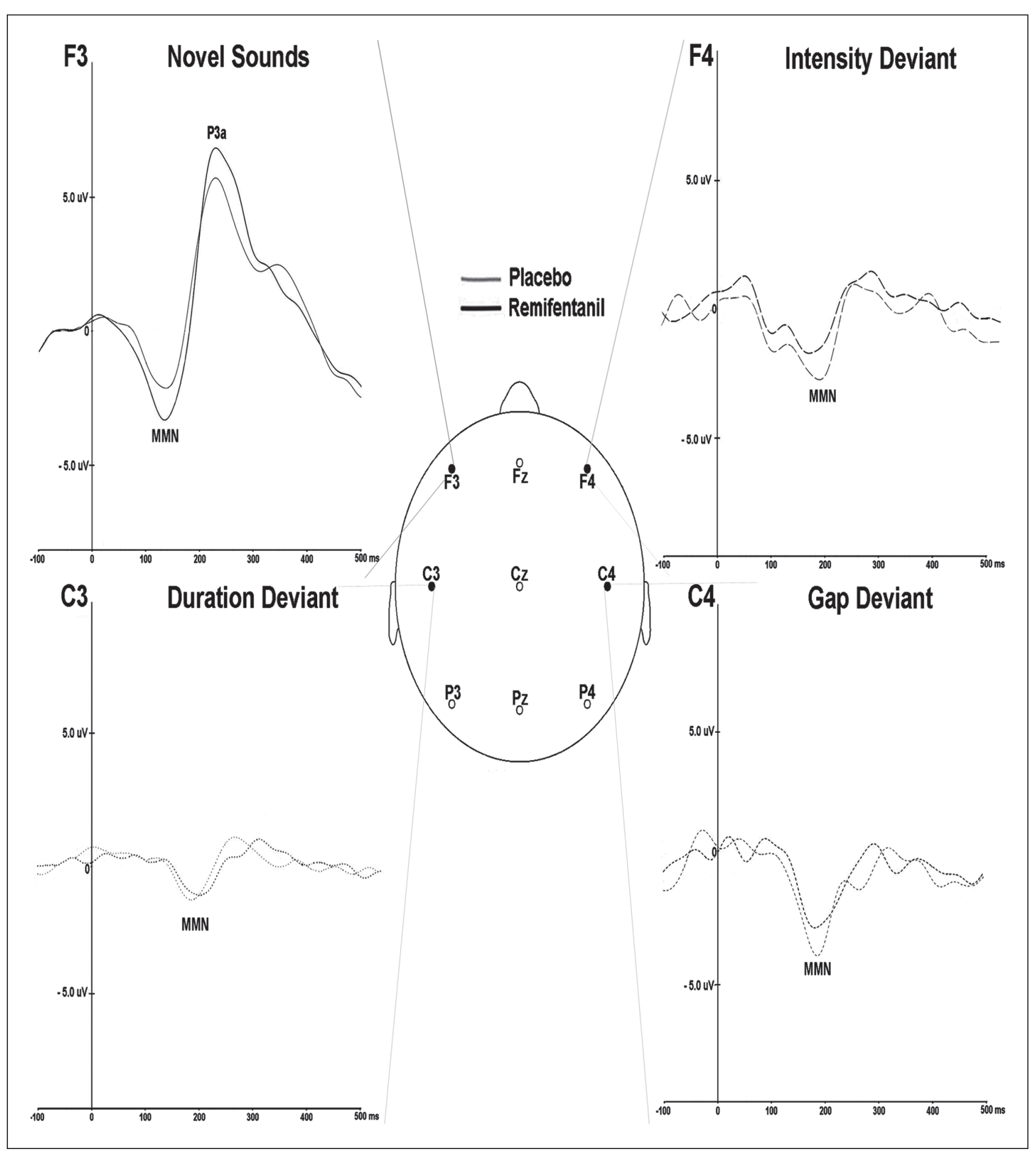

Figure 2. Grand average across participants of the difference wave (deviant/novel-standard) ERPs elicited by the MMN paradigm at the F3, F4, C3 and $\mathrm{C} 4$ electrodes. For the deviant sounds the MMN was observed around $150 \mathrm{~ms}$. For the novel sounds two peaks can be seen representing the MMN and P3a. The image of the head depicts the electrode positions used for the recording of the electroencephalographic data.

amplitude of the MMN(m) while controlled top-down auditory processing was quantified as the amplitude of the $\mathrm{P} 3 \mathrm{a}(\mathrm{m})$ (Friedman et al., 2001; Näätänen et al., 2011; Polich, 2007). For the MMN a gender effect was found for the frequency stimuli. Remifentanil increased the amplitude of the MMN on F3 in females but not in males. Again, no effect of treatment was found for the novel P3a, indicating that the top-down controlled switching of attention to the novel sound was not affected by remifentanil.

Remifentanil resulted in an increase in the amplitude of the frequency MMN for females. This is in line with previous studies showing that remifentanil increased the bold response and regional 


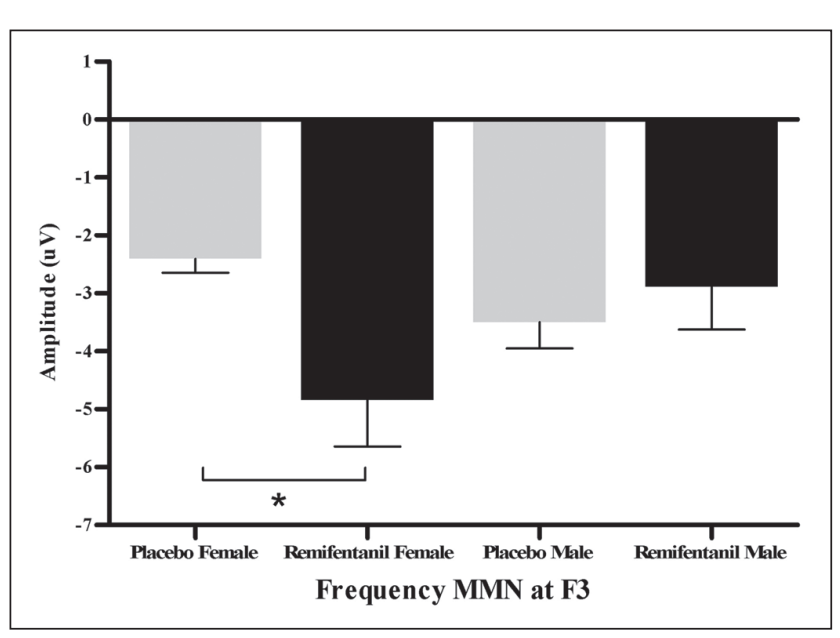

Figure 3. Comparison of the frequency MMN mean amplitudes at F3 in both genders separately. Remifentanil appeared to increase the female frequency MMN (ANOVA: $p=.013$ ).

cerebral blood flow in areas rich in MORs related to pain processing, for example the anterior cingulate and frontal cortex and in the temporal cortex involved in auditory processing (Leppa et al., 2006; Wagner et al., 2001). These findings disagree to some extent with the results of Haenggi et al. (2004), who did not find any effect of remifentanil on the amplitude of the mismatch negativity. However, the sample in the study of Haenggi et al. (2004) consisted of only male participants. The female-specific effect found in this study might be explained by gender differences in the density and distribution of opioid receptors (Craft, 2003). Specifically, females demonstrate a greater sensitivity to mu-opioid analgesia than males (Hurley and Adams, 2008), a finding that is likely accounted for by the higher MOR binding in the amygdala, thalamus, cerebellum, prefrontal, parietal and temporal cortex among women (Wiesenfeld-Hallin 2005; Zubieta et al., 1999). In this regard, it is conceivable that remifentanil modulates auditory processing by influencing the thalamocortical loop involved in regulating ascending sensory information flow. In addition, previous research showed that the gonadal steroid system modulates the opioid system (Craft 2003; Craft et al., 2004), although it is not yet known on which level. Craft et al. (2004) suggested that oestrogens may have directly activating effects on the opioid system or have organizational effects during development, resulting in distinct neuronal circuits regulating analgesic intensity. It is interesting that we found a remifentanil-induced enhancement of the MMN specifically for stimuli deviating in frequency from the standard stimuli. Previous research has also found unique effects on specific mismatch deviant types in several disorders. For example, Näätänen and Kujala (2011) found a decreased duration and an increased frequency deviant MMN in autism, and a specific duration deviant MMN decrement has been found in schizophrenia (Atkinson et al., 2012), suggesting that different mismatch types represent different constructs. Still, given the exploratory nature of the current study and the specificity of the effect, the findings should be interpreted with caution.

In general, the results showed that the event-related fields were larger in the right hemisphere compared with the left hemisphere. The above-discussed treatment effect with regard to the frequency
MMN was also only found in the right hemisphere. It has been suggested that the right hemisphere is more involved in sound change detection whereas the left hemisphere is related to speech processing (e.g. Alho et al., 1998; Levanen et al., 1996). Moreover, a right hemispheric network is suggested to be notably involved in target detection, stimulus evaluation and working memory including the anterior cingulate cortex, temporal and superior parietal and frontal cortex (e.g. Escera and Corral, 2007; Gilmore et al., 2009). In effect, the sound change detection network localized in the right hemisphere makes it plausible that we only found a treatment effect of the opioid remifentanil in the right hemisphere. In addition, novel sounds elicited earlier and larger event-related fields and potentials than deviant tones. This is in agreement with previous studies (Escera et al., 1998; Tiitinen et al., 1994) and with the fMRI study of Stevens et al. (2005), and might indicate that novel sounds caused more effective switching of attention (Friedman et al., 2001).

We found an effect of remifentanil for the amplitude of the frequency $\mathrm{MMN}$ in the EEG data while the MEG did not reveal any effect. This discrepancy might be accounted for by the technical differences between those two techniques. MEG detects mainly tangentially currents which compose the early MMN component generated in the auditory cortex. This early component is suggested to represent the automatic change detection, while the late component reflects the automatic bottom-up reorientation of attention. The late component is radially oriented and originates from the frontal cortex (Näätänen et al., 2007, 2011; Rinne et al., 2000). The MMN in the EEG represents both MMN subcomponents as EEG detects both kinds of currents. The remifentanil effect was only found in the EEG data which includes the frontally generated automatic attention component. This might imply that the automatic reorientation of attention is affected by remifentanil. This is in accordance with the suggested role for the opioid system in regulation of auditory attention mechanisms (e.g. Arnsten et al., 1984, Jaaskelainen et al., 1998). In agreement with this, Kivisaari et al. (2007) did not find any differences in the latency or strength of the $\mathrm{MMN}(\mathrm{m})$ in opioid-dependent patients. For the EEG data, they found a delayed MMN response to novel sounds, suggesting that the automatic reorientation of attention is particularly affected in opioid-dependent patients.

Some limitations of this study should be mentioned. First of all, we used a passive paradigm in which participants should ignore stimuli. However, it is very difficult to determine the extent to which participants are actually ignoring the stimuli. Unintended attention to the stimuli might influence the results. Secondly, differences in adverse effects caused by remifentanil are known. Therefore all participants took part in the behavioural pretest. It might be that the participants were not totally blinded to the saline control and the impact of expectance of opioid effects cannot be ruled out. Thirdly, an interesting and important question is the localization of the found effect. However, source localization could not be performed in the current study due to missing MRI images and too few EEG electrodes assessed. Future studies should integrate EEG and MEG or use high density EEG to assess the spatial localization of the studied effect. Finally, the used sample size was relatively small. Animal studies have revealed an inverse relation between opioid efficacy and the magnitude of the gender difference in analgesia (Craft, 2003). Remifentanil is a potent mu-opioid which will probably result in a small gender difference. 
Table 2. Summary of MEG results. Mean \pm S.E.M. (in parentheses) of $M M N(m)$ amplitudes $(\mathrm{fT} / \mathrm{cm})$ for difference waves (deviant/novel soundstandard) in the time windows used for the statistical analysis (see materials and methods) for the right and left hemisphere separately in the remifentanil and placebo condition. $p$-values less than .025 were considered as statistically significant.

\begin{tabular}{|c|c|c|c|c|c|}
\hline & & Hemisphere & Condition & Mean (S.E.M.) & Sig. \\
\hline \multirow[t]{20}{*}{ MMNm } & Novel & LH & Placebo & $28.13(4.30)$ & $F(1,18)=2.11 ; p=.16$ \\
\hline & & & Remifentanil & $31.42(4.01)$ & \\
\hline & & $\mathrm{RH}$ & Placebo & $32.49(3.49)$ & $F(1,16)=0.022 ; p=.88$ \\
\hline & & & Remifentanil & $32.49(3.49)$ & \\
\hline & Gap & LH & Placebo & $13.14(1.44)$ & $F(1,18)=2.56 ; p=.13$ \\
\hline & & & Remifentanil & $15.16(1.49)$ & \\
\hline & & $\mathrm{RH}$ & Placebo & $15.25(1.28)$ & $F(1,18)=0.25 ; p=.62$ \\
\hline & & & Remifentanil & $16.23(1.44)$ & \\
\hline & Intensity & LH & Placebo & $20.56(2.33)$ & $F(1,17)=0.72 ; p=.41$ \\
\hline & & & Remifentanil & $18.53(2.48)$ & \\
\hline & & RH & Placebo & $23.86(2.56)$ & $F(1,18)=3.70 ; p=.07$ \\
\hline & & & Remifentanil & $27.82(2.75)$ & \\
\hline & Duration & LH & Placebo & $22.00(2.36)$ & $F(1,18)=1.73 ; p=.20$ \\
\hline & & & Remifentanil & $24.66(2.30)$ & \\
\hline & & RH & Placebo & $28.03(3.13)$ & $F(1,18)=1.79 ; p=.20$ \\
\hline & & & Remifentanil & $33.04(4.00)$ & \\
\hline & Frequency & LH & Placebo & $21.70(1.87)$ & $F(1,18)=3.75 ; p=.07$ \\
\hline & & & Remifentanil & $24.00(2.27)$ & \\
\hline & & $\mathrm{RH}$ & Placebo & $28.66(3.05)$ & $F(1,18)=1.13 ; p=.30$ \\
\hline & & & Remifentanil & $31.51(2.93)$ & \\
\hline
\end{tabular}

Table 3. Summary of the EEG results. Mean \pm S.E.M. (in parentheses) of the novel P3a amplitudes $(\mu \mathrm{V})$ for difference waves (novel-standard) in the time windows 190-290 ms on the F3. F4, C3, C4, P3 and P4 electrodes in both conditions. $p$-values less than .008 were considered as statistically significant.

\begin{tabular}{|c|c|c|c|c|c|}
\hline & & Electrode & Condition & Mean (Std. Error) & Sig. \\
\hline \multirow[t]{12}{*}{ P3a } & Novel & F3 & Placebo & $5.66(0.72)$ & $F(1,18)=2.42 ; p=.14$ \\
\hline & & & Remifentanil & $6.88(1.05)$ & \\
\hline & & $\mathrm{F} 4$ & Placebo & $6.38(0.75)$ & $F(1,18)=1.03 ; p=.32$ \\
\hline & & & Remifentanil & $7.21(1.13)$ & \\
\hline & & C3 & Placebo & $6.17(0.86)$ & $F(1,18)=2.68 ; p=.12$ \\
\hline & & & Remifentanil & $7.26(0.97)$ & \\
\hline & & $\mathrm{C} 4$ & Placebo & $5.32(1.01)$ & $F(1,18)=3.29 ; p=.09$ \\
\hline & & & Remifentanil & $6.90(0.85)$ & \\
\hline & & P3 & Placebo & $2.96(0.63)$ & $F(1,18)=2.05 ; p=.17$ \\
\hline & & & Remifentanil & $3.84(0.58)$ & \\
\hline & & $\mathrm{P} 4$ & Placebo & $3.21(0.65)$ & $F(1,18)=0.94 ; p=.34$ \\
\hline & & & Remifentanil & $3.79(0.55)$ & \\
\hline
\end{tabular}

Consequently, a large sample size will be needed in future studies to reliably detect gender differences.

In summary, our results suggest that the bottom-up stimulus change detection system appears to be relatively insensitive to opioids whereas the automatic attentional switch caused by the change detection is modulated by the opioid system in females. The multiple deviant paradigm including novel sounds is a promising tool for investigating pharmacological manipulation of different stages of auditory and attentional processing. This study has shown that MEG and EEG are complementary in the field of MMN research as they both detect a different subcomponent of the MMN, yielding more specific knowledge about the stage of effect of drug treatments. Measuring ERPs as an objective marker of the pain-relieving effects of analgesics seems a promising avenue. Yet, our findings call for a systematic investigation of potential moderators in the effects of opioids on the MMN, such as gender differences. Eventually, this might contribute to our understanding of the pre-attentive processing abnormalities found in chronic pain and the involvement of the opioid system. 


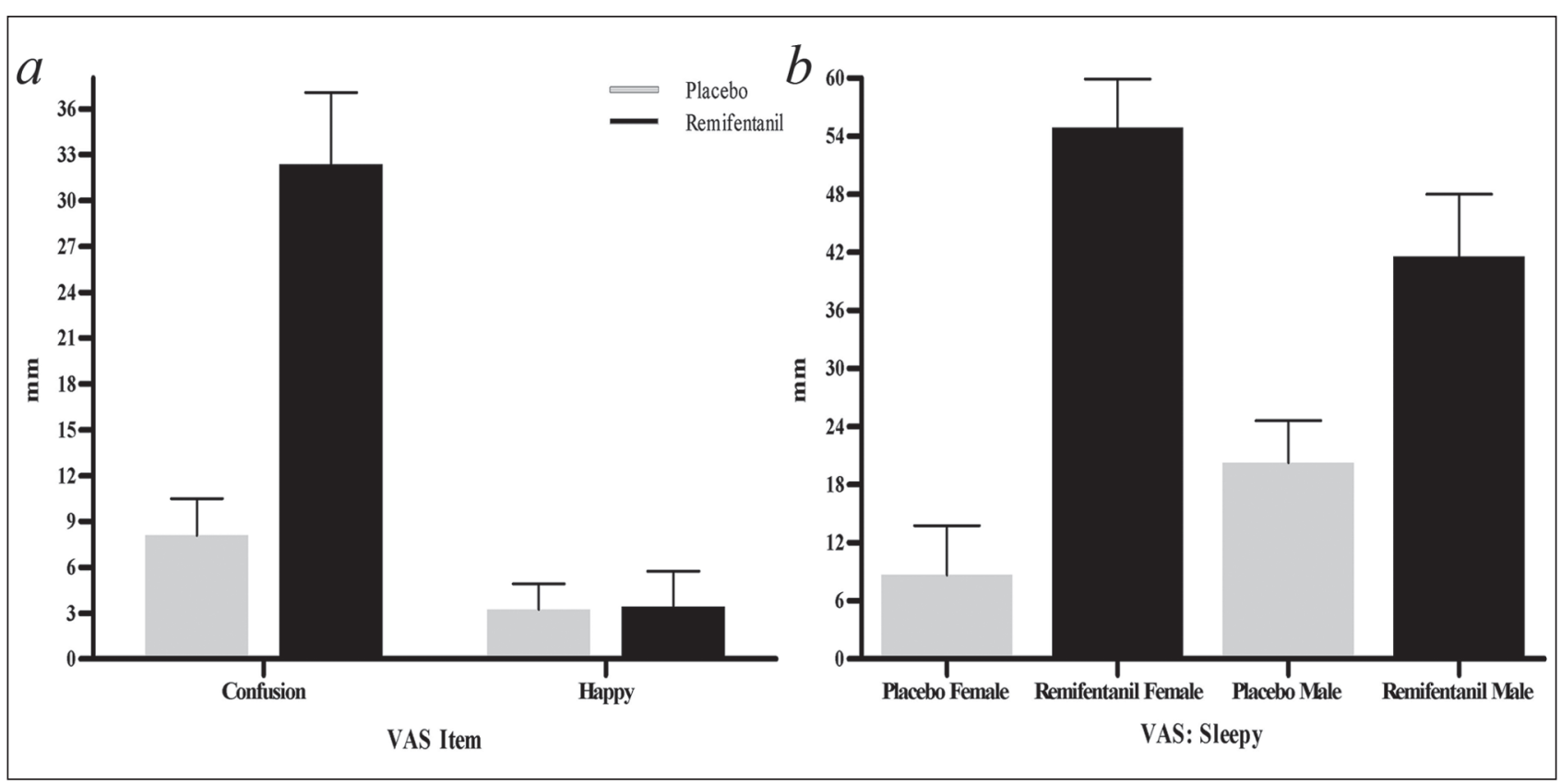

Figure 4. Subjective effects of remifentanil measured with the VAS scales. Panel $a$ : participants felt more confused but remifentanil did not affect mood. Panel $b$ : participants felt sleepier with a larger effect in females. Graphs show means \pm SD.

\section{Acknowledgements}

We are especially grateful to Jyrki Mäkelä, Juha Montonen and Seppo Kähkönen for the technical assistance and help in data collection.

\section{Conflict of interest}

E.K. has received speaker's fees from Janssen-Cilag, MSD, Mundipharma, Pfizer, and Pharmaleads and consultancy honoraria from Gruenenthal and Pfizer.

\section{Funding}

This work was supported in part by Grant from the Helsinki University Central Hospital Research Funds [TYH 2009217].

\section{References}

Alho K, Connolly JF, Cheour M, et al. (1998) Hemispheric lateralization in preattentive processing of speech sounds. Neurosci Lett 258: 9-12.

Alho K, Huotilainen M, Tiitinen H, et al. (1993) Memory-related processing of complex sound patterns in human auditory cortex: A MEG study. Neuroreport 4: 391-394.

Arnsten AF, Neville HJ, Hillyard SA, et al. (1984) naloxone increases electrophysiological measures of selective information processing in humans. J Neurosci 4: 2912-2919.

Atkinson RJ, Michie PT and Schall U (2012) Duration mismatch negativity and P3a in first-episode psychosis and individuals at ultra-high risk of psychosis. Biol Psychiatry 71: 98-104.

Battershill AJ and Keating GM (2006) Remifentanil : A review of its analgesic and sedative use in the intensive care unit. Drugs 66: 365-385.

Beers R and Camporesi E (2004) Remifentanil update: Clinical science and utility. CNS Drugs 18: 1085-1104.

Breen D, Karabinis A, Malbrain M, et al. (2005) Decreased duration of mechanical ventilation when comparing analgesia-based sedation using remifentanil with standard hypnotic-based sedation for up to 10 days in intensive care unit patients: A randomised trial. Crit Care 9: R200-R210.
Brush DR and Kress JP (2009) Sedation and analgesia for the mechanically ventilated patient. Clin Chest Med 30: 131-141, ix.

Cabanero D, Celerier E, Garcia-Nogales P, et al. (2009) The pro-nociceptive effects of remifentanil or surgical injury in mice are associated with a decrease in delta-opioid receptor mRNA levels: Prevention of the nociceptive response by on-site delivery of enkephalins. Pain 141 : 88-96.

Ceponiene R, Lepisto T, Soininen M, et al. (2004) Event-related potentials associated with sound discrimination versus novelty detection in children. Psychophysiology 41: 130-141.

Craft RM (2003) Sex differences in opioid analgesia: "From mouse to man". Clin J Pain 19: 175-186.

Craft RM, Mogil JS and Aloisi AM (2004) Sex differences in pain and analgesia: the role of gonadal hormones. Eur J Pain 8: 397-411.

Dahaba AA, Grabner T, Rehak PH, et al. (2004) Remifentanil versus morphine analgesia and sedation for mechanically ventilated critically ill patients: A randomized double blind study. Anesthesiology 101: 640-646.

Dick BD, Connolly JF, McGrath PJ, et al. (2003) The disruptive effect of chronic pain on mismatch negativity. Clin Neurophysiol 114: 1497-1506.

Escera C and Corral MJ (2007) Role of mismatch negativity and novelty-P3 in involuntary auditory attention. J Psychophysiol 21: 251-264.

Escera C, Alho K, Winkler I, et al. (1998) Neural mechanisms of involuntary attention to acoustic novelty and change. $J$ Cogn Neurosci 10 : 590-604.

Friedman D, Cycowicz YM and Gaeta H (2001) The novelty P3: An event-related brain potential (ERP) sign of the brain's evaluation of novelty. Neurosci Biobehav Rev 25: 355-373.

Garrido MI, Kilner JM, Stephan KE, et al. (2009) The mismatch negativity: A review of underlying mechanisms. Clin Neurophysiol 120: 453-463.

Giard MH, Perrin F, Pernier J, et al. (1990) Brain generators implicated in the processing of auditory stimulus deviance: A topographic eventrelated potential study. Psychophysiology 27: 627-640.

Gilmore CS, Clementz BA and Berg P (2009) Hemispheric differences in auditory oddball responses during monaural versus binaural stimulation. Int J Psychophysiol 73: 326-333. 
Haenggi M, Ypparila H, Takala J, et al. (2004) Measuring depth of sedation with auditory evoked potentials during controlled infusion of propofol and remifentanil in healthy volunteers. Anesth Analg 99: $1728-1736$

Hämäläinen M, Hari R, Ilmoniemi RJ, et al. (1993) Magnetoencephalography - theory, instrumentation, and applications to noninvasive studies of the working human brain. Rev Mod Phys 65: 413-497.

Hillebrand A and Barnes GR (2002) A quantitative assessment of the sensitivity of whole-head MEG to activity in the adult human cortex. Neuroimage 16: 638-650.

Hurley RW and Adams MCB (2008) Sex, gender, and pain: An overview of a complex field. Anesth Analg 107: 309-317.

Jaaskelainen IP, Hirvonen J, Kujala T, Measuring depth of sedation with auditory evoked potentials during controlled infusion of propofol and remifentanil in healthy volunteers (1998) Effects of naltrexone and ethanol on auditory event-related brain potentials. Alcohol 15: 105-111.

Jasper HH (1958) The ten-twenty electrode system of the International Federation. Electroencephalogr Clin Neurophysiol 10: 371-375.

Julien RM (2005) A primer of drug addiction. New York: Worth Publishers.

Kahkonen S (2006) Magnetoencephalography (Meg): A non-invasive tool for studying cortical effects in psychopharmacology. Int J Neuropsychopharmacol 9: 367-372.

Kenemans JL and Kähkönen S (2011) How human electrophysiology informs psychopharmacology: From bottom-up driven processing to top-down control. Neuropsychopharmacology 36: 26-51.

Kivisaari R, Lehtinen R, Autti T, et al. (2007) Impaired pre-attentive auditory processing in opioid dependence with and without benzodiazepine co-dependence revealed by combined magnetoencephalography and electroencephalography. Prog Neuropsychopharmacol Biol Psychiatry 31: 1378-1386.

Korostenskaja M, Nikulin VV, Kicic D, et al. (2007) Effects of NMDA receptor antagonist memantine on mismatch negativity. Brain Res Bull 72(4-6): 275-283.

Kujala T, Tervaniemi M and Schroger E (2007) The mismatch negativity in cognitive and clinical neuroscience: Theoretical and methodological considerations. Biol Psychol 74: 1-19.

Lauwers MH, Vanlersberghe C and Camu F (1998) Comparison of remifentanil and propofol infusions for sedation during regional anesthesia. Reg Anesth Pain Med 23: 64-70.

Leppa M, Korvenoja A, Carlson S, et al. (2006) Acute opioid effects on human brain as revealed by functional magnetic resonance imaging. Neuroimage 31: 661-669.

Levanen S, Ahonen A, Hari R, et al. (1996) Deviant auditory stimuli activate human left and right auditory cortex differently. Cereb Cortex 6: $288-296$

Lopes da and Silva FH (2010) Electrophysiological basis of MEG Signals. In: Hansen P, Kringelbach M and Salmelin R (eds) MEG: An Introduction into Methods. Oxford: Oxford University Press, pp.5-27.

Maatta S, Paakkonen A, Saavalainen P, et al. (2005) Selective attention event-related potential effects from auditory novel stimuli in children and adults. Clin Neurophysiol 116: 129-141.

Minto CF, Schnider TW and Shafer SL (1997) Pharmacokinetics and pharmacodynamics of remifentanil. II. Model application. Anesthesiology 86: 24-33.

Munte S, Quaedflieg CWEM, Sambeth A, et al. (2013) Effects of remifentanil on cognitive and psychomotor functioning and mood. $\mathrm{Br} \mathrm{J}$ Anaesth 111: 517-518.

Näätänen R and Kujala T (2011) The mismatch negativity and its magnetic equivalent: An index of language impairment or more general cognitive decline in autism? Biol Psychiatry 70: 212-213.

Nätänen R and Picton T (1987) The N1 wave of the human electric and magnetic response to sound: A review and an analysis of the component structure. Psychophysiology 24: 375-425.

Näätänen R, Kujala T and Winkler I (2011) Auditory processing that leads to conscious perception: A unique window to central auditory processing opened by the mismatch negativity and related responses. Psychophysiology 48: 4-22.
Näätänen R, Paavilainen P, Alho K, et al. (1989) Do event-related potentials reveal the mechanism of the auditory sensory memory in the human brain? Neurosci Lett 98: 217-221.

Näätänen R, Paavilainen P, Rinne T, et al. (2007) The mismatch negativity (MMN) in basic research of central auditory processing: A review. Clin Neurophysiol 118: 2544-2590.

Näätänen R, Pakarinen S, Rinne T, et al. (2004) The mismatch negativity (MMN): Towards the optimal paradigm. Clin Neurophysiol 115: 140-144.

Pakarinen S, Takegata R, Rinne T, et al. (2007) Measurement of extensive auditory discrimination profiles using the mismatch negativity $(\mathrm{MMN})$ of the auditory event-related potential (ERP). Clin Neurophysiol 118: 177-185.

Panzer O, Moitra V and Sladen RN (2009) Pharmacology of sedativeanalgesic agents: Dexmedetomidine, remifentanil, ketamine, volatile anesthetics, and the role of peripheral mu antagonists. Crit Care Clin 25: 451-469, vii.

Papanicolaou AC (1995) An introduction to magnetoencephalography with some applications. Brain Cogn 27: 331-352.

Peng J, Sarkar S and Chang SL (2012) Opioid receptor expression in human brain and peripheral tissues using absolute quantitative realtime RT-PCR. Drug Alcohol Depend 124: 223-228.

Polich J (2007) Updating P300: An integrative theory of P3a and P3b. Clin Neurophysiol 118: 2128-2148.

Rinne T, Alho K, Ilmoniemi RJ, et al. (2000) Separate time behaviors of the temporal and frontal mismatch negativity sources. Neuroimage 12 : $14-19$.

Sambeth A, Huotilainen M, Kushnerenko E, et al. (2006) Newborns discriminate novel from harmonic sounds: A study using magnetoencephalography. Clin Neurophysiol 117: 496-503.

Sambeth A, Pakarinen S, Ruohio K, et al. (2009) Change detection in newborns using a multiple deviant paradigm: A study using magnetoencephalography. Clin Neurophysiol 120: 530-538.

Scott LJ and Perry CM (2005) Remifentanil: A review of its use during the induction and maintenance of general anaesthesia. Drugs 65: 1793-1823.

Stevens MC, Calhoun VD and Kiehl KA (2005) Hemispheric differences in hemodynamics elicited by auditory oddball stimuli. Neuroimage 26: 782-792.

Tiitinen H, May P, Reinikainen K, et al. (1994) Attentive novelty detection in humans is governed by pre-attentive sensory memory. Nature 372: 90-92.

Tongjaroenbuangam W, Jongkamonwiwat N, Phansuwan-Pujito P, et al. (2006) Relationship of opioid receptors with GABAergic neurons in the rat inferior colliculus. Eur J Neurosci 24: 1987-1994.

Umbricht D, Schmid L, Koller R, et al. (2000) Ketamine-induced deficits in auditory and visual context-dependent processing in healthy volunteers: Implications for models of cognitive deficits in schizophrenia. Arch Gen Psychiatry 57: 1139-1147.

Wagner KJ, Willoch F, Kochs EF, et al. (2001) Dose-dependent regional cerebral blood flow changes during remifentanil infusion in humans: A positron emission tomography study. Anesthesiology 94: 732-739.

Wiesenfeld-Hallin Z (2005) Sex differences in pain perception. Gend Med 2: $137-145$.

Wise RG, Williams P and Tracey I (2004) Using fMRI to quantify the time dependence of remifentanil analgesia in the human brain. Neuropsychopharmacology 29: 626-635.

Woldorff MG, Hackley SA and Hillyard SA (1991) The effects of channel-selective attention on the mismatch negativity wave elicited by deviant tones. Psychophysiology 28: 30-42.

Yao SQ, Liu XH, Yang WH, et al. (2011) Preattentive processing abnormalities in chronic pain: Neurophysiological evidence from mismatch negativity. Pain Med 12: 773-781.

Zubieta JK, Dannals RF and Frost JJ (1999) Gender and age influences on human brain mu-opioid receptor binding measured by PET. Am J Psychiatry 156: 842-848. 